\title{
Competency Based Nursing Curriculum: Establishing the Standards for Nursing Competencies in Higher Education
}

\author{
Olfat A. Salem ${ }^{1,2}$, Ahmad E. Aboshaiqah1, Murad A. Mubaraki3 ${ }^{3}$ Isabelita N. Pandaan4 \\ ${ }^{1}$ Nursing Administration and Education Department, College of Nursing, King Saudi University, Riyadh, Saudi Arabia \\ ${ }^{2}$ Nursing Administration Department, Faculty of Nursing, Menofia University, Shebeen El-Kom, Egypt \\ ${ }^{3}$ Clinical Laboratory Sciences Department, College of Applied Medical Sciences, King Saudi University, Riyadh, Saudi Arabia \\ ${ }^{4}$ Medical Surgical Department, College of Nursing, King Saud University, Riyadh, Saudi Arabia \\ Email: *osalem@ksu.edu.sa
}

How to cite this paper: Salem, O.A., Aboshaiqah, A.E., Mubaraki, M.A. and Pandaan, I.N. (2018) Competency Based Nursing Curriculum: Establishing the Standards for Nursing Competencies in Higher Education. Open Access Library Journal, 5: e4952.

https://doi.org/10.4236/oalib.1104952

Received: September 30, 2018

Accepted: November 6, 2018

Published: November 9, 2018

Copyright $\odot 2018$ by authors and Open Access Library Inc.

This work is licensed under the Creative Commons Attribution International License (CC BY 4.0).

http://creativecommons.org/licenses/by/4.0/

\begin{abstract}
Competency is the basic standard for all healthcare professionals when providing care to recipients. The practice of good nursing begins primarily in the study of the nursing program and in the preparation of a nurse with high efficiency in nursing skills. This paper presents the concept of nursing competencies for Saudi nursing and its importance in implementing the national transition program 20/30, and the nursing competencies framework related to the graduate of the Bachelor of Nursing and the methods used in response to the needs of the academic and educational environment, and the stages to develop a competency-based approach.
\end{abstract}

\section{Subject Areas}

Education

\section{Keywords}

Competence Based Learning, Nursing Skills, Nursing Education

\section{Background}

Determining the quality of student learning is an ongoing challenge to all educators. With ever changing demand for quality and safe nursing practice, as well as the emergence of innovation in technology in health care settings, educators are faced with a myriad of issues that surround the quality of learning reflecting certain standards and describe essential attributes vital for transforming a novice 
to an expert. When the healthcare professionals are required to deliver an acceptable performance within the context of the standards identified by the regulatory bodies, the academe is commissioned to train the students in such a manner that the outcome of learning exhibits the proficiency expected.

\subsection{Recognizing Competency/Commentary}

In the nursing profession, competency is essential and providing a clear theoretical definition of competency is only the first step [1]. A systematic literature review on competency based learning emphasized that, competency is explained as a combination of attributes enabling performance of a range of professional tasks in accordance to the appropriate standards [2]. An emphasis was placed on the heightened levels of public concern regarding safety are also a major factor which mandates that health professionals demonstrate clinical competence prior to entering the clinical setting [3].

Nurse professionals have a distinct commitment to develop and implement the standards of nursing practice through continuous acquisition of pertinent knowledge, attitude and skills, application of critical judgment, and the evaluation of such as essential to quality care. In like manner, in a safe and high-quality system of care health professionals are required to take responsibility to learn and apply skills associated with improving a wider system of care. Nurses are accountable and are held liable for their actions in the clinical field [4]. The assurance of continued competence is an essential element through which commitment should begin. Additionally, continuing competence is ongoing professional nursing competence according to the level of expertise, responsibility, and domains of practice [5].

However, competency encompasses more than just psychomotor skills. Competency specifies the level of achievement expected and the tasks and contexts of professional practice in which we may see the competency demonstrated [2]. Nurses know that psychomotor skills are important but without the requisite of knowledge, it does not constitute nursing. Knowledge of health and disease process is of little use with the appropriate nursing skills to apply. Planning and organizing capabilities are of little benefit to the clients if the attitude that a nurse should value (such as caring and patience) is not present. Therefore, the integration of the three domains is essential for understanding and eventually performing nursing care with competence. The Canadian Nurses Association further emphasized that safe, competent, and ethical nurse practitioner practice requires the integration and performance of many competencies simultaneously [6].

One factor given cognizance in competency that contributes to nursing quality is the nurse's years of experience in nursing. Multiple experiences of observing cues, and recognizing patterns related to patient status that need to be acted on in specific ways, lead to higher levels of clinical performance. Expert practitioners' supplement formal learning with mature knowledge which is based on the 
progress has taken years to take place [7].

\subsection{Undergraduate Nursing Competency Curriculum Development}

Students have innate abilities and attitudes that they carry upon entry into the nursing program. This is where the process of education begins. As soon as the courses are introduced, the knowledge and skills specific to nursing are presented. Within these times, the students and the educators engage in various activities that integrate knowledge and skills for caring to inculcate the desirable competency required by the learners.

Discussed in recent researches, new graduates are not well prepared for their duties in the field [8]. Moreover, it was noted that it took approximately eight months of clinical experience before new Bachelor Science Nursing graduates felt confident and competent in their clinical judgments [9].

As the nursing education to tertiary settings is progressing, the nature of the learning and application has also been altered. Nursing courses for enrolled and registered nurses remain on the basis of knowledge; skills and attitudes that nurses are expected to demonstrate in the workplace in a wide variety of contexts and settings. Thus, competency-based Education has been introduced to some professional programs and courses such as nursing.

In light with this with this development, it is also recognized that a competency based approach requires the analysis of relevant and current environment and needs from which they determine content and competencies to be achieved in the instructional program. This provides a foundation of the competency outcomes together with adult education, interactive and student focused learning strategies, as well as outcomes and assessment of performance competencies. Competency based education or training emphasizes on assessment in real-life settings and situations. The evaluation is formed on how the learner is able to create judgment and demonstrate the knowledge based on the clinical scenario [10].

Also, a competency-based performance evaluation assess a participant's actual ability to meet a predetermined set of performance standards under controlled conditions and protocols and is focused on knowledge and principles essential for effective implementation of required skills [11].

\section{The Innovation: The Process Establishing Competency-Based Curriculum}

College of Nursing aims to provide safe, competent and ethical nursing care to Saudis. To accomplish this goal, College of Nursing identified the need to establish a new approach. Undergraduate nursing competency based curricular content presents key pedagogical challenges that concerns within the guidelines of the curriculum was developed,

A multi-step process was utilized to define the set of nursing core competencies for the nursing program. Firstly, identified and created competencies based 
on a benchmarked from other countries and current trends and standard practices in USA. A review of the Quality and Safety Education for Nurses model (Quality and Safety Education for Nurses (QSEN)) [12] was done. A review of literature, conducted and compared the set of core competencies against internationally accepted models, guideline and standards. The preliminary set of competencies was also compared to the Essentials of Baccalaureate of Education (American Association of Colleges of Nursing [13], the Competency Outcomes and Performance Assessment (COPA) model [10] and the National League for Nursing's educational competencies for graduates of associate degree nursing programs (National League for Nursing (NLN)) [14].

Figure 1 shows the competency framework which the first dynamics was resulting to defining the competency of the nursing curriculum. This laid down the foundation of the competency to be implemented and described the importance of these competencies to the college. Seven (7) competencies were recognized. Specifically, these competencies are caring, professionalism, communication, leadership, safety, research and teaching and learning. The established competency model addresses the current need of the nursing education specifically in the Saudi Nursing Curriculum.

Additionally, to develop the nursing competencies, a set of assumptions were also identified to serve as a framework for its work and as guiding principles for the design of a competency-based education and practice partnership model. Table 1 reflects these assumptions.

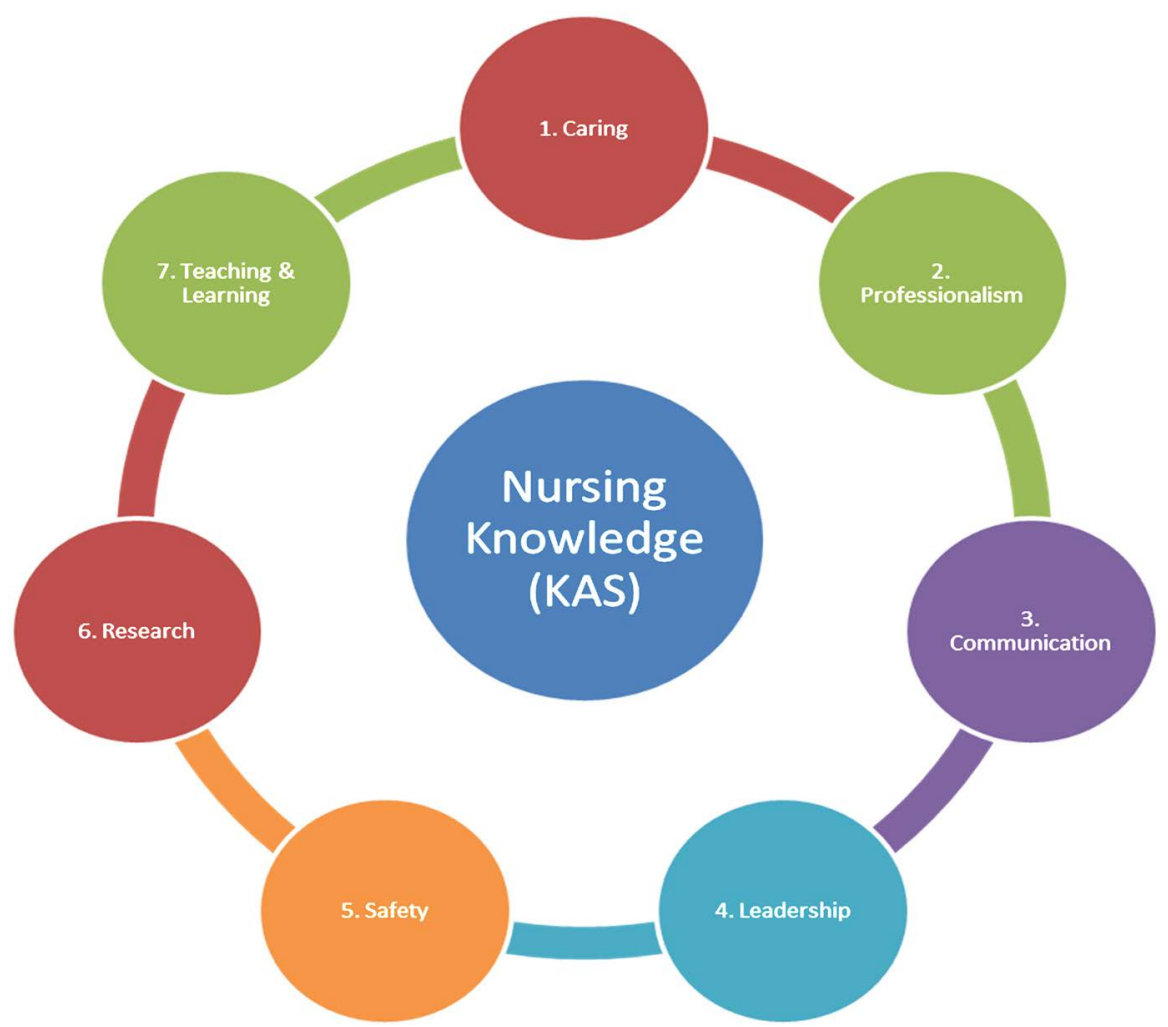

Figure 1. Competency framework (KAS: Knowledge, Attitude, Skills). 
Furthermore, the second phase was to specify and delineate these competencies by defining them and categorizing the skills relative to each competency. Table 2 reflects the defined core competencies; lastly, develop the assessment tools applicable for the competence required.

\subsection{Maintaining the Standards of the Profession}

Having identified and clear core competencies, it is essential to integrate these competencies into the training provided for the nursing students. It is requisite of all courses that all nursing students should be able to meet their respective

Table 1. Assumptions as framework and guiding principles for a competency-based education and practice partnership model.

The competency-based education are based on the following assumptions:

- Education and practice partnerships are fundamental to developing an effective model.

- It is imperative that leaders in nursing education and practice shall develop collaborative curriculum models to facilitate the achievement of a minimum of a baccalaureate degree in nursing by all nurses.

- A more effective educational system must be developed, one capable of incorporating shifting demographics and preparing the nursing workforce to respond to current and future health care needs and health issues.

- The nurses of the future will be proficient in a core set of competencies.

- Nurse educators in the academe and in practice settings will need to use different set of knowledge and teaching strategies to effectively integrate the nursing core competencies of the future into the curriculum.

Table 2. Definition of core competencies.

\begin{tabular}{|c|c|c|}
\hline No & Core Competencies & Definition \\
\hline 1 & $\begin{array}{c}\text { Patient-Centered } \\
\text { Care (Caring) }\end{array}$ & $\begin{array}{l}\text { Provide holistic care that recognizes an individual's preference, values } \\
\text { and needs. It also respects the patients and treats them as a full partner } \\
\text { in providing compassionate, coordinated and culturally appropriate, } \\
\text { safe and effective care. }\end{array}$ \\
\hline 2 & Professionalism & $\begin{array}{l}\text { Demonstrate accountability for practicing nursing within established } \\
\text { moral, legal, ethical, regulatory, and humanistic principles. }\end{array}$ \\
\hline 3 & Communication & $\begin{array}{l}\text { It refers to the ability to interact effectively with patient, families, and } \\
\text { colleagues, fostering mutual respect and shared decision-making, to } \\
\text { enhance patient satisfaction and health outcomes. }\end{array}$ \\
\hline 4 & Leadership & $\begin{array}{l}\text { The leadership in nursing is regarding capability to influence the } \\
\text { behavior of individuals or groups of individuals within their } \\
\text { environment in a way that will facilitate the establishment and } \\
\text { acquisition/achievement of shared goals. }\end{array}$ \\
\hline 5 & Safety & $\begin{array}{l}\text { Minimize risk of harm to patients and providers through both system } \\
\text { effectiveness and individual performance. }\end{array}$ \\
\hline 6 & Research & $\begin{array}{l}\text { Integrate best current evidence with clinical expertise and consideration } \\
\text { of patients' preference experience and values for delivering the best } \\
\text { quality of care. }\end{array}$ \\
\hline 7 & $\begin{array}{l}\text { Teaching and } \\
\text { Learning }\end{array}$ & $\begin{array}{l}\text { Comprehends the basic principle of learning and teaching and learning } \\
\text { domain. Furthermore, a sense of awareness for health literacy and } \\
\text { cooperative learning is determined. }\end{array}$ \\
\hline
\end{tabular}


competencies for the beginning practitioner. Multiple requirements for competent nursing practice in the health care system have been established by national associations and agencies. The Joint Commission for Accreditation of Health Care Organizations obliges that the clinical competence should be assessed, maintained, demonstrated, and continually improved [9]. Taking these clear set of standards, these form a basis for those within the specialty, and other collaborating part of the academe to understand the competencies required for practice. The competency-based standards offer a basis for judgments to be made for entry into the profession, such as accreditation, registration, or enrolment as a nurse. They also provide clear guidelines for judging progression within the role, and as such can be used to make decisions about awards, classifications, promotions, and for general staff appraisal purposes.

\subsection{Developing the Skill Competency Guidelines}

As part of the multi-step approach, guidelines for the competency-based curriculum proposed. Purpose, policy, procedure, remediation, professional behaviors, clinical safety policy, and list of clinical skills are components of the guidelines. Primarily, the purpose of the competency is to evaluate and assess student's skill competency level. The main policy generalizes that all nursing students will be required to demonstrate competencies in; medication administration, nursing skills, and professional documentation.

In the guidelines, a detailed description of the competency testing is provided. In addition, as postulated in the procedure section of the guidelines students will demonstrate competencies at the pre-novice level at the end of each year. Remediation is defined as a practice required for all unsuccessful skill testing. This addresses concerns for students who demonstrate unsatisfactory completion of the competency test [15]. There are three main steps of remediation and each of them has a specific guideline. However, after the third remediation, if the students are unsuccessful, they will be considered to be failed in the course.

To evaluate a student's clinical practice that whether it is safe or not, the clinical safety policy is established. It is expected that all students will deliver nursing care in a safe manner.

\subsection{The Current Evaluation Methods}

Evaluation of learning and the concomitant exploration and development of appropriate models and techniques for assessment, have always been a significant component of the curriculum within the College of Nursing.

Regardless of whether the unit is theoretical or practical, our students are provided with a unit outline specifying rationale, course outcomes and objectives, content, pedagogical approach for teaching nursing skills, assessment requirements, and criteria for assessment. The learning goals, instructional design and evaluation of learning methods are all linked and clearly visible. That offers the learner an opportunity to safely acquire clinical skills in a controlled, structured 
manner

As claimed earlier, the College of Nursing competency standards form the basis of our Clinical Performance Evaluation Tool. This tool is currently designed around seven competency clusters; patient-centered (caring competency), professionalism, communication, leadership, safety, research, teaching, and learning. A guide providing the details against which a student's clinical performance is evaluated accompanies each Tool. Each student must achieve a satisfactory level of performance in each of the competencies contained in the seven clusters. Identified indicators are used by the evaluators to judge the level of performance.

\section{Conclusion}

This competence based curriculum innovation shifted the nature of the educator-learner relationship, the way learners interacted with the material, and how this was connected with clinical practice. Shifting the nature of the relationship made room for much creativity, depth, and exploration; safe practice for success, as well as mistakes that could be corrected; and the opportunity to focus on difficult-to-reach aspects of nursing skills and early graduate clinical experiences. The authors believe that this competence based curriculum will impact practice by alerting new graduates to potential skills issues as they are in transition; the experience will offer them possible solutions to difficult and often unexplored aspects of their beginning practice. Competency is central to nursing practice and it is a critical contemporary issue to ensure a future supply of high quality nursing care. There is much work to be done to examine the effectiveness of competence based curriculum innovation. Future research examining the use of competency developed would make a major contribution to this field.

\section{Conflicts of Interest}

The authors declare no conflicts of interest regarding the publication of this paper.

\section{References}

[1] Axley, L. (2008) The Integration of Technology into Nursing Curricula: Supporting Faculty via the Technology Fellowship Program. Online Journal of Issues in Nursing, 13.

[2] Gruppen, L.D., Mangrulkar, R.S. and Kolars, J.C. (2012) The Promise of Competency-Based Education in the Health Professions for Improving Global Health. Human Resources for Health, 10, 43. https://doi.org/10.1186/1478-4491-10-43

[3] Davis, B. and Sumara, D. (2010) "If Things Were Simple...": Complexity in Education. Journal of Evaluation in Clinical Practice, 16, 856-860. https://doi.org/10.1111/j.1365-2753.2010.01499.x

[4] Dolansky, M.A. and Moore, S.M. (2013) Quality and Safety Education for Nurses (QSEN): The Key Is Systems Thinking. The Online Journal of Issues in Nursing, 18, 1. 
[5] Decker, S., Utterback, V.A., Thomas, M.B., Mitchell, M. and Sportsman, S. (2011) Assessing Continued Competency through Simulation: A Call for Stringent Action. Nursing Education Perspectives, 32, 120. https://doi.org/10.5480/1536-5026-32.2.120

[6] Canadian Nurses Association (2010) Canadian Nurse Practitioner: Core Competency Framework.

[7] Hill, K. (2010) Improving Quality and Patient Safety by Retaining Nursing Expertise. Online Journal of Issues in Nursing, 15, 1-9.

[8] Wykoff, R., Khoury, A., Stoots, J.M. and Pack, R. (2014) Undergraduate Training in Public Health Should Prepare Graduates for the Workforce. Frontiers in Public Health, 2, 285.

[9] Redman, R.W., Lenburg, C.B. and Hinton Walker, P. (1999) Competency Assessment: Methods for Development and Implementation in Nursing Education. Online Journal of Issues in Nursing, 4, 1-7.

[10] Lenburg, C.B., Klein, C., Abdur-Rahman, V., Spencer, T. and Boyer, S. (2009) The COPA Model: A Comprehensive Framework Designed to Promote Quality Care and Competence for Patient Safety. Nursing Education Perspectives, 30, 312-317.

[11] Tilley, D.D.S. (2008) Competency in Nursing: A Concept Analysis. The Journal of Continuing Education in Nursing, 39, 58-64. https://doi.org/10.3928/00220124-20080201-12

[12] (2010) Quality and Safety Education for Nurses Update. Leader to Leader, Nursing Regulation \& Education Together. https://www.ncsbn.org/L2L_Fall2010.pdf

[13] American Association of Colleges of Nursing (2008) The Essential of Baccalaureate Education for Professional Nursing Practice.

[14] National League for Nursing (2000) Educational Competencies for Graduates of Associate Degree Nursing Programs.

[15] Henderson, K.L. (2010) The Remediation of Students in Counselling Graduate Programs: Behavioural Indicators, Terminology, and Interventions. ProQuest Dissertations Publishing, University of New Orleans, New Orleans. 